\title{
Plantas Aquáticas e Nível de Infestação das Espécies Presentes no Reservatório de Bariri, No Rio Tietê ${ }^{1}$
}

\author{
Aquatic Plants and Infestation Level at the Bariri Reservoir in Tietê River, Brazil
}

\author{
CARVALHO, F.T. ${ }^{2}$, VELINI, E.D. ${ }^{3}$ e MARTINS, D. ${ }^{4}$
}

\begin{abstract}
RESUMO - O monitoramento da vegetação aquática permite avaliar a evolução das comunidades e determinar o potencial de danos associados a essas populações. O objetivo do trabalho foi identificar as plantas aquáticas e os níveis de infestação de cada espécie, presentes no reservatório de Bariri. Foram avaliados todos os focos de vegetação aquática presente na represa (194 pontos), e os pontos foram demarcados com um aparelho de GPS. As plantas foram identificadas e realizou-se uma estimativa visual do valor geográfico do ponto (tamanho da área) e a distribuição proporcional das plantas no foco de infestação. Foram encontradas 15 espécies de plantas aquáticas vegetando na represa de Bariri. Considerando que as principais espécies ocorreram com niveis de infestação acima de $10 \%$, as mais importantes foram: Brachiaria mutica $(27,0 \%$ da área e $97,4 \%$ de freqüência), B. subquadripara $(22,7 \%$ da área e $96,9 \%$ de freqüência), Eichhornia crassipes (13,8\% da área e $85,6 \%$ de freqüência) e Typha angustifolia $(16,7 \%$ da área e $72,7 \%$ de freqüência). Outra espécie que pode ser destacada e que apresentou um bom potencial de infestação foi Enidra sessilis, que ocorreu em $8,9 \%$ de ocupação na área vegetada e com $76,3 \%$ de freqüência.
\end{abstract}

Palavras-chave: planta daninha, levantamento, monitoramento, reservatório.

\begin{abstract}
Aquatic vegetation monitoring allows to evaluate community evolution and to determine the potential of damages associated to these populations. The objective of this work was to identify the aquatic plants and infestation levels of each species in the Bariri reservoir in the state of São Paulo, Brazil. All the aquatic vegetation foci in the dam (194 points) were evaluated and marked with GPS equipment. The plants were identified and a visual estimate of the geographic value of the point (size of the area) and a proportional distribution of the plants in the focus were carried out. Fifteen macrophyte species were found vegetating in the Bariri dam. Due to the great diversity of the species found, those presenting infestation levels above 10\% were considered to be the major ones. Therefore, the most important aquatic species were: Brachiaria mutica, Brachiaria subquadripara, Eichhornia crassipes and Typha angustifolia. Another species that may be considered prominent with an index between $5 \%$ and $10 \%$ and a good infestation potential was Enidra sessilis.
\end{abstract}

Key words: weed, assessment, monitoring,reservoir.

\section{INTRODUÇÃO}

As plantas aquáticas são estudadas como um efeito do desequilíbrio causado pela poluição e/ou alagamento dos rios. A quantidade excessiva de plantas, conseqüente desse desequilíbrio, dificulta a navegação, a produção de energia elétrica e outras atividades desenvolvidas em ambientes aquáticos (Carvalho et al., 2003).

A importância das plantas aquáticas na manutenção do equilíbrio natural de ambientes aquáticos é indiscutivel, uma vez que elas realizam fotossintese e conseqüente oxigenação da água, servindo de fonte de alimento e

Recebido para publicação em 20.1.2005 e na forma revisada em 22.3.2005.

2 Prof. Dr., Dep. de Biologia e Zootecnia, FEIS/UNESP, Av. Brasil, no 56, Centro, 15385-000 Ilha Solteira-SP, $<$ ftadeu@bio.feis.unesp.br>; ${ }^{3}$ Prof. Dr., Departamento de Produção Vegetal, FCA/UNESP, Fazenda Experimental Lageado, Caixa Postal 237, 18603-970 Botucatu-SP; ${ }^{4}$ Prof. Livre Docente., Dep. de Produção Vegetal, F. Exp. Lageado, FCA/UNESP, Botucatu-SP. 
refúgio para peixes, aves e outros organismos (Tanaka 1998; IBAMA, 1998; Thomaz \& Bini, 2002). Entretanto, em condições de desequilíbrio, os prejuízos são muito maiores que os beneficios (Fernandez et al., 1990; Marcondes \& Tanaka, 1997; Pitelli, 1998; Smith et al., 1999; Van Nes et al., 2002; Tanaka et al., 2002; Thomaz \& Bini, 2002), podendo, inclusive, ocorrer morte de peixes por desequilíbrio na oxigenação. No caso de plantas submersas, a fotossintese enriquece a oxigenação durante o dia, porém, à noite, a respiração reduz drasticamente os niveis de oxigênio da água, podendo causar a morte de peixes.

No rio Tietê, nas áreas mais distantes das regiões poluídas dos grandes centros urbanos, à medida que se aproxima de sua foz (o rio Paraná), ocorre aumento gradativo das condições ecológicas favoráveis à ocorrência de plantas submersas. Nesse ambiente, o alagamento (que transformou o rio de lótico, ou seja, com corredeiras, em lêntico) e a transparência natural das águas, relatada por Cavenaghi (2003), são os fatores predominantes. Dessa forma, no último reservatório do rio Tietê, em Três Irmãos, as plantas submersas são as mais abundantes (Tanaka et al., 2002); em compensação, no reservatório mais distante da foz, em Barra Bonita, não ocorrem plantas submersas (Carvalho et al., 2003).

O monitoramento periódico das macrófitas aquáticas permite avaliar a evolução das comunidades e determinar o potencial de danos associados a essas populações. A identificação de focos iniciais de plantas de alto risco para a produção de energia elétrica é bastante importante na tomada de decisões quanto à erradicação ou não destes focos.

Assim, o objetivo deste trabalho foi identificar as plantas aquáticas e os niveis de infestação de cada espécie, presentes no reservatório de Bariri, com o intuito de auxiliar na formação de uma base de dados para determinação do potencial de dano dessas populações ao ambiente e à utilização da água para suas várias finalidades, especialmente a geração de energia elétrica.

\section{MATERIAL E MÉTODOS}

O levantamento das macrófitas foi feito no mês de julho de 2001. A locomoção no rio foi realizada por meio de um bote de $6 \mathrm{~m}$ de comprimento, movido a motor de popa de quatro tempos, com potência de $25 \mathrm{HP}$, a uma velocidade média de $35 \mathrm{~km} \mathrm{~h}^{-1}$ entre os pontos avaliados.

Ao longo do reservatório foram marcados 335 pontos de avaliação. O grande número de pontos no levantamento justifica-se pela elevada freqüência de pequenos grupos de plantas flutuantes no reservatório do rio Tietê.

Foram avaliados todos os focos de vegetação aquática marginal, flutuante, ancorada e imersa, presentes na represa de Bariri, no rio Tietê e afluentes, e os pontos foram demarcados com um aparelho de GPS (Global Position System). As plantas foram identificadas e realizou-se uma estimativa visual de valor geográfico do ponto (tamanho da área) e distribuição proporcional das plantas no foco.

A escala utilizada para a estimativa do tamanho da área (valor geográfico do ponto) variou de 0 a 15 , em que cada ponto correspondeu a, praticamente, 1 ha $(100 \mathrm{~m} \times 100 \mathrm{~m})$, sendo $0=$ nenhuma infestação e $15=$ maior área possível de ser avaliada visualmente. Esse parâmetro foi importante, pois permitiu avaliar não só a freqüência das plantas, como também o seu nível de infestação em toda a represa, valorizando a infestação em pontos maiores.

Quanto ao tamanho da área coberta por macrófitas aquáticas na represa de Bariri, durante o período de levantamento da flora, a estimativa foi feita através de dados de sensoriamento remoto, com aplicação em recursos naturais, obtidos de sensores instalados em plataformas orbitais (satélite Landsat), publicados por Galo et al. (2002).

\section{RESULTADOS E DISCUSSÃO}

A represa de Bariri representa o segundo alagamento do rio Tietê e, por isso, recebe muita influência da eutrofização de Barra Bonita. O reservatório de Bariri é o que apresenta o segundo maior índice de turbidez do rio Tietê (34,93 NTU), segundo Cavenaghi (2003); entretanto, nessas condições, já foi encontrada a espécie submersa Ceratophyllum demersum (Tabela 1). 
A represa de Bariri é formada pelo alagamento dos rios Tietê (Figura 1), Jaú e afluentes. A área ocupada pela represa foi de 5.318 ha, e a ocupada por macrófitas aquáticas, de 426 ha (Galo et al., 2002), ou seja, 8,0\% da área do reservatório.

As plantas daninhas aquáticas observadas na represa de Bariri estão apresentadas na Tabela 1.

Tabela 1 - Hidrófitas observadas e porcentagem média de ocupação de cada espécie na área total vegetada. Reservatório de Bariri (julho/2001)

\begin{tabular}{|c|c|c|c|c|}
\hline & Espécie Daninha & Nome Comum & $\begin{array}{c}\% \\
\text { Ocupação } \\
\text { na Área } \\
\text { Vegetada }\end{array}$ & $\begin{array}{c}\text { Frequiência } \\
(\%)\end{array}$ \\
\hline 1 & Brachiaria mutica & capim-de-angola & 27,0 & 97,4 \\
\hline 2 & Brachiaria subquadripara & tenner-grass & 22,7 & 96,9 \\
\hline 3 & Ceratophyllum demersum & ceratofilum & 0,1 & 1,0 \\
\hline 4 & Echinochloa polystachya & capim-arroz & 1,0 & 4,1 \\
\hline 5 & Eichhornia crassipes & aguapé & 13,8 & 85,6 \\
\hline 6 & Enidra sessilis & enidra & 8,9 & 76,3 \\
\hline 7 & Ipomoea alba & corda-de-viola & 0,1 & 1,0 \\
\hline 8 & Ludwigia elegans & ludivígia & 0,2 & 3,1 \\
\hline 9 & Myriophyllum aquaticum & miriofilum & 0,4 & 1,0 \\
\hline 10 & Panicum rivulare & panicum & 3,3 & 14,9 \\
\hline 11 & Paspalum repens & canarana & 1,4 & 19,6 \\
\hline 12 & Pistia stratiotes & alface-d'água & 2,9 & 34,0 \\
\hline 13 & Polygonum lapathifolium & erva-de-bicho & 0,5 & 8,2 \\
\hline 14 & Salvinia auriculata & salvínia & 1,0 & 3,6 \\
\hline 15 & Typha angustifolia & taboa & 16,7 & 72,7 \\
\hline \multicolumn{3}{|c|}{ TOTAL } & 100 & - \\
\hline
\end{tabular}

* Freqüência $=\%$ de pontos com plantas da espécie, em 194 pontos avaliados.

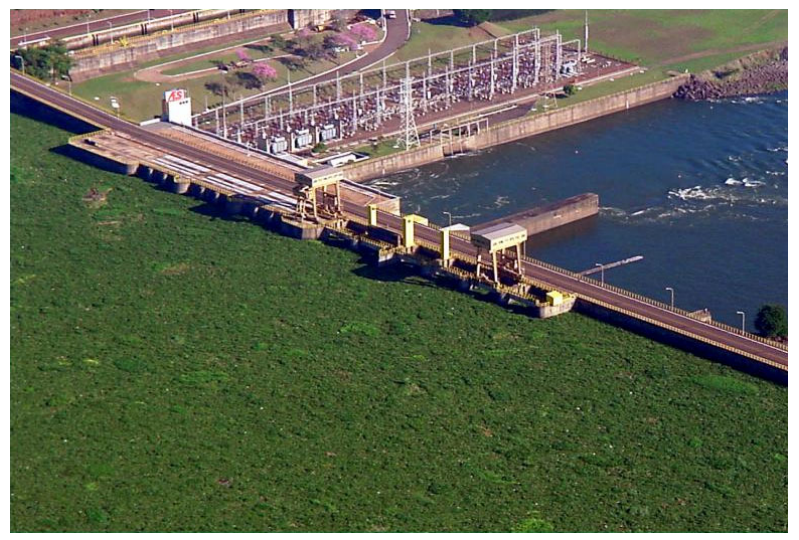

Fonte: Velini et al. (2005).

Figura 1 - Infestação de hidrófitas na barragem de Bariri, no rio Tietê (junho/2001). Fotografia aérea.

Observa-se que foram encontradas 15 espécies de plantas aquáticas vegetando no reservatório de Bariri. Devido ao grande número delas, não houve espécies dominantes (com mais de $50 \%$ de ocupação média da área vegetada); entretanto, algumas mostraram-se co-dominantes, a exemplo do reservatório de Barra Bonita (Carvalho et al., 2003). Considerando que as principais espécies (Figura 2) ocorreram com niveis de infestação acima de $10 \%$, as mais importantes foram: B. mutica (27,0\% da área e 97,4\% de freqüência),

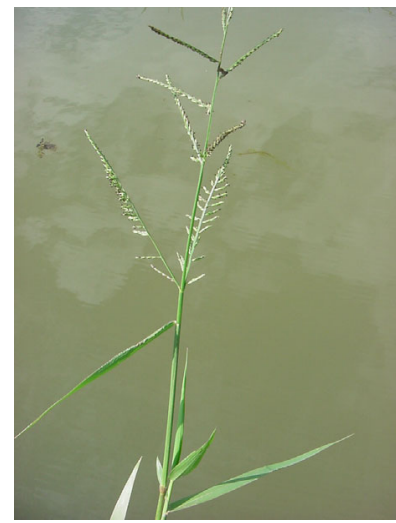

Brachiaria mutica

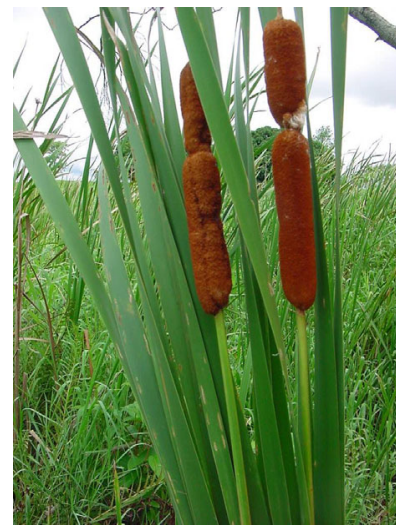

Typha angustifolia

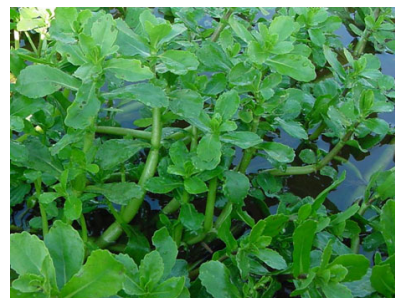

Enidra sessilis

Figura 2 - Principais espécies de plantas aquáticas observadas no reservatório de Bariri. Julho/2001.

Planta Daninha, Viçosa-MG, v. 23, n. 2, p. 371-374, 2005 
B. subquadripara $(22,7 \%$ da área e $96,9 \%$ de freqüência), E. crassipes $(13,8 \%$ da área e $85,6 \%$ de freqüência) e $T$. angustifolia $(16,7 \%$ da área e $72,7 \%$ de freqüência).

Outra espécie que pode ser destacada no reservatório de Bariri - que ocorreu com índice entre 5 e $10 \%$ e bom potencial de infestação foi $E$. sessilis, com $8,9 \%$ de ocupação na área vegetada e $76,3 \%$ de freqüência.

\section{LITERATURA CITADA}

CARVALHO, F. T. et al. Plantas aquáticas e nível de infestação das espécies presentes no reservatório de Barra Bonita, no Rio Tietê. Planta Daninha, v. 21, p. 15-19, 2003. (Edição especial)

CAVENAGHI, A. L. Caracterização da qualidade de água e sedimento relacionados com a concorrência de plantas aquáticas em cinco reservatórios da bacia do Rio Tietê. 2003. 73 f. Tese (Doutorado em Agronomia) Universidade Estadual de São Paulo, Botucatu, 2003.

FERNANDEZ, O. A. et al. Aquatic weed problems and management in South and Central America. In: PIETERSE, A. H.; MURPHY, K. J. Aquatic weeds: the ecology and management of nuisance aquatic vegetation. Oxford: Oxford University Press, 1990. p. 407-425.

GALO, M. B. L. T. et al. Uso do sensoriamento remoto orbital no monitoramento da dispersão de macrófitas nos reservatórios do Complexo Tietê. Planta Daninha, v. 20, p. 7-20, 2002. (Edição especial)

IBAMA Apresentação. In: WORKSHOP SOBRE CONTROLE DE PLANTAS AQUÁTICAS, 1998, Brasília. Anais... Brasília: IBAMA, 1998. p. 2-4.
MARCONDES, D. A. S.; TANAKA, R. H. Plantas aquáticas nos reservatórios das usinas hidrelétricas da CESP. In: CONGRESSO BRASILEIRO DA CIÊNCIA DAS PLANTAS DANINHAS, 21., Caxambu, 1997. Workshop de Plantas Aquáticas... Viçosa, MG: SBCPD, 1997. p. 2-4.

PITELLI, R. A. Macrófitas aquáticas no Brasil, na condição de problemáticas. In: WORKSHOP SOBRE CONTROLE DE PLANTAS AQUÁTICAS, 1998, Brasília. Anais... Brasília: IBAMA, 1998. p. 32-35.

SMITH, B. E.; LANGELAND, K. A.; HANLON, C. G. Influence of foliar exposure, adjuvants and rain-free period on the efficacy of glyphosate for torpedograss control. J. Aquat. Plant. Manag., v. 37, p. 13-16, 1999.

TANAKA, R. H. et al. Ocorrência de plantas aquáticas nos reservatórios da Companhia Energética de São Paulo. Planta Daninha, v. 20, p. 99-111, 2002. (Edição especial)

TANAKA, R. H. Prejuízos provocados por plantas aquáticas. In: WORKSHOP SOBRE CONTROLE DE PLANTAS AQUÁTICAS, 1998, Brasília. Anais... Brasília: IBAMA, 1998. p. 36-38.

THOMAZ, S. M.; BINI, L. M. A expansão das macrófitas aquáticas e implicações para o manejo de reservatórios: Um estudo na represa Itaipu. In: HENRY, R. (Ed.) Ecologia de reservatórios: estrutura, função e aspectos sociais. Botucatu: FUNDIBIO, 1999. p. 597-626.

VELINI, E. D. et al. Assessment of aquatic plants in the reservoirs of AES-Tietê and development of an integrated control model for the most important species. J. Environ. Sci. Heal.,vBb40, p. 85-110, 2005.

VAN NES, E. H. et al. Aquatic macrophytes: restore, eradicate or is there a compromise. Aquat. Botany, v. 72, p. 387-403, 2002. 